\title{
解析・設計解探索融合による 電子デバイス配置熱設計手法*
}

\section{岩田剛 治 ${ }^{* *}$}

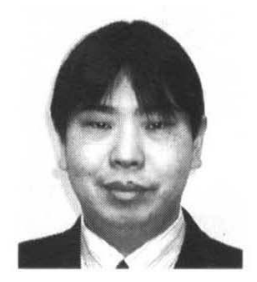

\author{
Thermal Layout Design for Electronics Devices by Fusing Analysis Method and \\ Optimum Method* \\ by IWATA Yoshiharu ${ }^{* *}$ \\ キーワードシステムデザイン, 電子システム, 電子デバイス, 配置設計, 概略熱設計, 高速熱解析, \\ モジュール化モデル, 階層化設計, 解析・設計解探索融合設計手法
}

\section{1.はじめに}

近年, 各種製品の高機能化・高性能化に伴い, 製品シ ステムの複雑度が非常に高くなってきている，そのため, 製品前設計時に製品全体を見通す事が困難になってきて いる、そのため，これまでは製品全体を見通せるシステ 么設計者による各要素技術に対して適切な仕様設計を行 うことが困難になってきている，そのため，これまでの 与えられた仕様に基づく要素技術の積み上げによる設計 だけでなく, システムに要求されている仕様からくるト ップダウン的な設計技術が必要である。 しかもその設計 においては自然科学の観点のみではなく経済的な観点も 網羅した中での設計解の探索 (最適化) の研究が注目さ れてきており，本年度からは日本学術振興会にシステム 系としては初めての「システムデザイン・インテグレー ション研究委員会」が設立される等の動きがある.

一方, 現在, 設計に扔いて使用される解析手法と最適 化手法は独立に進化してきている。しかし，これらを組 み合わせてシステムレベルの設計を行うと, 時間と精度 の両立が困難であった。これに対して，これまでは，モ デルを簡素化し, 簡単な解析手法を構築し, それと沉用 の最適化手法を組み合わせる手法の研究 きたが，これは従来の枠組みの延長でしかない。しかも， この場合，システム全体を扱うシステムデザインでは対 象の設計変数が多く, その選択肢も多い組合せ最適化問 題となり, 非常に多数の解析が必要になるため, やはり 時間がかかってしまい, 特に製品寿命が短く設計時間が とれない製品では大きな問題となる.

そこで本稿では, システムデザイン・インテグレーシ

*原䆆受付 平成17年10月12日

**正員大阪大学 Member, Osaka University
ヨン技術の一部をなす複雑系の最適化問題へのアプロー チとして, 解析手法・解探索手法融合高速概略設計手法 に関して, 特に製品寿命が短く, 設計時間が短いモバイ ル端末での，デバイス配置・熱管理設計をケーススタデ イとして, 構築した筆者の研究を紹介する.

\section{2. 解析時間短縮の追求と沉用最適化 手法の組合せの限界}

電子デバイスの熱管理は, モバイル端末等の低消費電 力機器の場合は, ファンによる冷却では無く, 熱伝導に よる熱の拡散と端末表面からの空冷で行われる。このシ ステムの熱伝導解析における高速解析手法としては, 高 速回路解析を利用する等価熱回路網解析手法（熱の流れ を電流の流れに置き換える）等のコンパクトモデリング の手法 ${ }^{-8}$ が提案されてきている. しかし, 解析は解析, 設計解探索は設計解探索という枠組みは変わっていない. なぜなら,これまでの電子デバイスの熱管理は, 回路設 計者の決めた回路基板上のデバイスの配置 ${ }^{9-12)}$ を前提に, 熱管理のみを設計者の経験と勘により行われてきたため, 秒単位の解析時間以上の高速化は行われていないのが現 状である.

そのため, 電子デバイスの回路基板上のレイアウトに 関して, 熱問題の増大に対しては, 現状では, 回路設計 者が詳細な回路設計を行う前の概略配置設計段階で消費 電力密度という間接的な概念でしか取り扱えていない. この問題を解決するためには, 下流の詳細熱設計だけで はどうにもならず，昨今重要性が叫ばれている設計の上 流側13, 11)である概略配置設計での対応が必要である。 その ため, 電子デバイスの概略配置設計段階で概略熱管理設 計も同時に行う必要がある。しかし、これにより設計変 数は 2 倍になり, 設計解の探索空間の次元数も 2 倍にな り，そのサイズは膨大になる。そのために，設計解の探 
索空間の増大に伴う解析回数の増大を隇らし, 熱伝導解 析を取り込み，適切に熱問題を考虑できる概略配置設計 手法の構築と, それに必要な熱解析手法が必要となる. その一方, 1 回の概略配置設計に費やせる設計時間は 1 時間程度しか無い。

そこで，筆者らは概略配置設計段階で構築できる概略 熱モデルを，熱の流れに着目し，図 1 に示すような, 設 計対象システム (CPU, 制御用 LSI, メモリ，I/O を想定) を、デバイスモジュール（LSI とその接合部を含む）と， 基板モジュールに分割して，独立に解析・設計ができる 様に構築した。 また, 対象の温度変化が $80^{\circ} \mathrm{C}$ 程度と小さ い時は, 解析モデルを線形にしても誤差が $3 \%$ 以下程度 になる事らから，解析手法も線形解析とした。これにより， 重冨解析が可能となり, モデル化した時のモジュール化 を有効に利用できるようになった。その結果，図 2 に示 すような $50 \mathrm{~mm}$ 角の基板上に $10 \mathrm{~mm}$ 角のデバイスを 4 個搭載した電子システムの解析を，並列計算を用いるこ となく数 ms で行える解析手法を構築できた（図 3 ) 16.17). しかし，本手法と沉用の最適化手法（遺伝的アルゴリズ ム：GA）を組み合わせて解探索を行った結果，予想通り 数日脚けても解探索が収束せず，概略配置設計に用いる ことは難しいことが確認された。そこで, 新たな設計技 術 (設計解探索) の構築を行った.

\section{3. 巨大設計パラメータ空間で必要と される解析手法・解探索手法融合 設計手法の構築}

それでは，なぜ最新の汎用最適化手法を用いても設計
解を探索できなかったのかについて検討を行う。この原 因としては，まだ確たる報告はないが，最適化手法の研 究者の間では, 設計空間が巨大で，その中で制約条件を 満たす空間が非常に小さい領域にしか存在しない場合は, $\mathrm{GA}$ 等のアルゴリズムの適用が困難になるという説が有力 である、つまり, システムデザインの課題は, 最適解の 探索が困難になることであると言える.

実際，今回ケーススタディで用いた簡単な設計対象で も,デバイスの実装部の熱抵抗を単純な 2 抵抗モデルと した場合, デバイスの位置と合わせて 1 つのデバイス毎 に設計変数が 4 個になる. 回路基板にデバイスが 4 個搭 載された場合では, 設計変数が16個にもなる。この時の 解の組合せは $6 \times 10^{24}$ となり, その探索空間は広大な領域 となっている.

そこで，筆者らは本稿のシステムのモデル化の特徴を 利用して, 設計を複数の階層に分割する階層化設計手法 を構築した，そのフローチャートを図 4 に示す.

この設計手法では, 一番上位の階層はデバイスモジュ ールレイアウトの設計階層である. 次の階層はモジュー ル間の境界条件の設計階層で, 最後の階層はデバイスモ ジュール内部の設計階層である。これにより, 各設計階 層における設計パラメー夕は激減し, 最大でも 2 つの設 計パラメー夕を扱うのみとすることにより, 設計解探索 空間を著しく縮小した。そのため, 設計階層によっては, 最新の汎用最適化手法を用いるよりも, サンプリング手 法（離散化した総当たり）の方が早く探索できるように なり，一定誤差内で確実に近似最適解を探索できるサン プリング手法が使えるようになった。

また, 各設計階層での設計解の探索領域をモデルの特

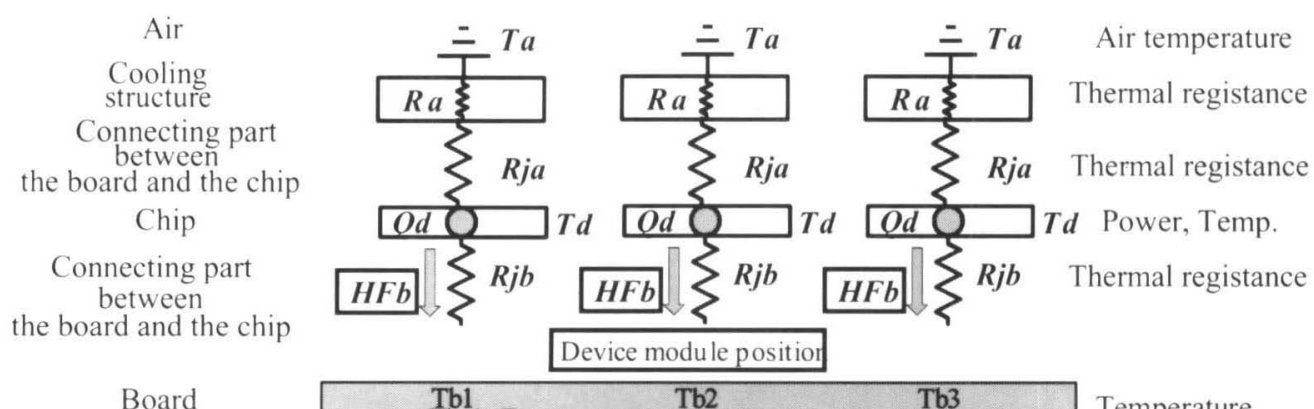

Board

\begin{tabular}{|c|c|c|}
\hline $\begin{array}{l}\text { Tbl } \\
+\mathrm{Tbs} 1+\mathrm{Ta}\end{array}$ & $\begin{aligned} & \mathrm{Tb} 2 \\
&+\mathrm{Tbs} 2+\mathrm{Ta}\end{aligned}$ & $\begin{aligned} & \mathrm{Tb} 3 \\
&+\mathrm{Tbs} 3+\mathrm{Ta}\end{aligned}$ \\
\hline
\end{tabular}

図 1 モジュール化モデル

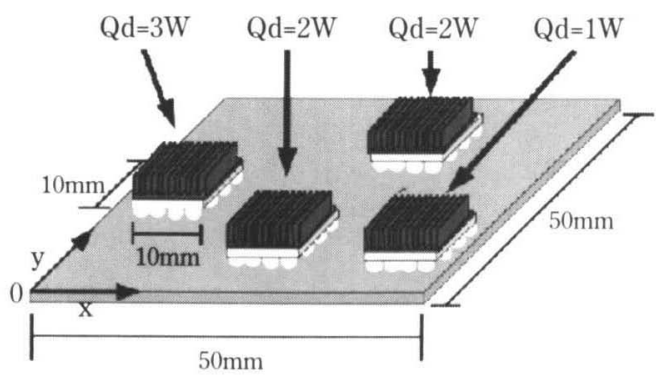

図2 電子システムのイメージ

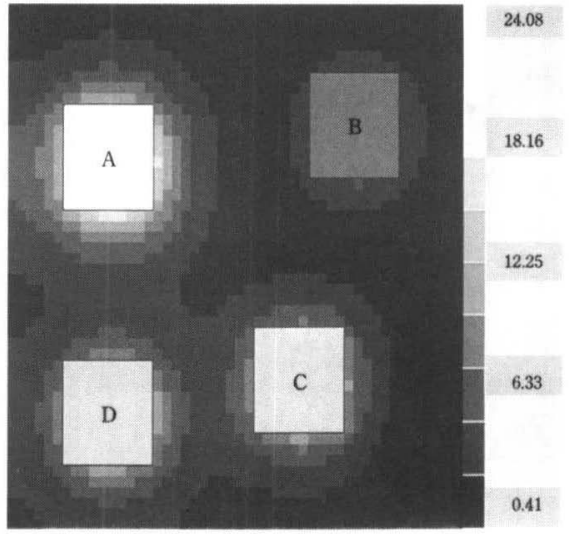

図 3 熱解析の結果例 
徵と解析時の中間データを利用して, その時々の状況に 応じて適応制御された探索空間を構築している.これは, 設計解の探索状況ごとに変動する設計パラメータの取り うる上下限值を, 解析の中間データである重畳前の個別 のデバイスモジュールが作る温度分布の数学的操作によ り高速導出している。これにより, 設計階層毎での, き め細かい探索範囲の設定が可能になり, 設計解の探索効 率と探索速度が向上した.

さらに, 本稿の熱解析ではデバイスモジュールと基板 モジュールの間の境界条件を導出するために, 約百回の

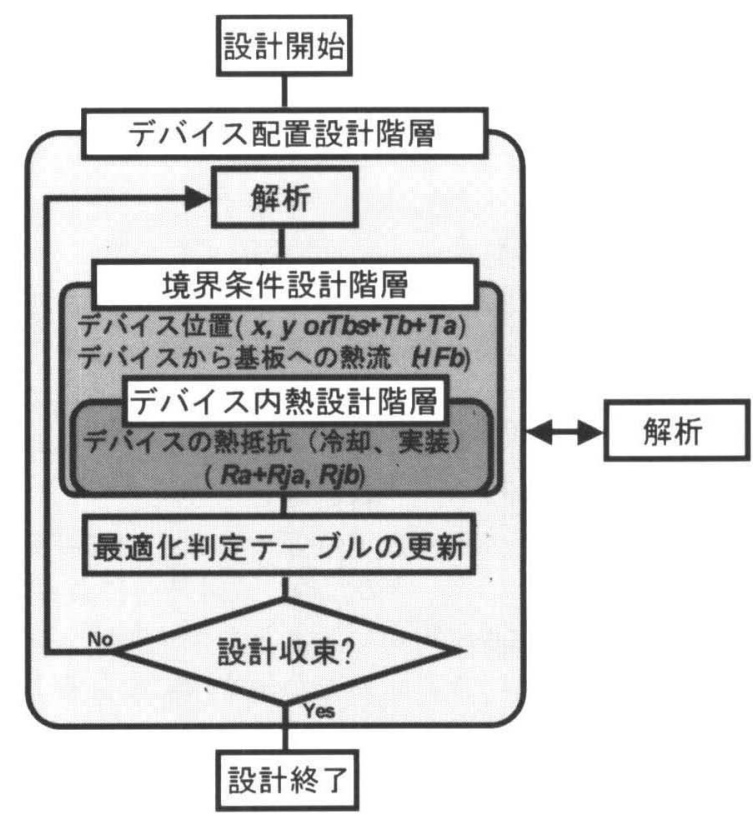

図 4 階層化設計手法のフローチャート
収束計算（反復計算）を行っている。そして，本設計手 法では,この熱解析は, 階層化設計手法の最下層でモデ ルデータが決定した時に呼び出されることになる.ここ で，注目すべきはモジュール間の境界条件を設計值とし ているため, 最下層ではこの境界条件が既知の状態とな っている事である. ということは，階層化設計手法を用 いることにより熱解析に必要であった収束計算が不要と なり, 熱解析速度は収束計算に必要であった反復回数倍 高速化され, 熱解析速度は数十 $\mu \mathrm{s}$ 程度となり, これまで に例を見ない高速な解析が可能になる。

これらの解析技術と解探索技術との融合の結果, 熱解 析回数が数百万回（設計時間約 100 秒）でデバイスの配 置・熱管理設計解が図 5 のように導出できるようにな り ${ }^{18)}$, コーヒーで一服する時間で設計解を導出できるよ うになった。これにより，これまで，多くの設計パター ンを考えることが出来なかった設計者に対して, 本手法 による高速な解の導出は大きな支援になっているといえ る.

\section{4. 回路設計との協調とその他の展開}

現在, 本手法は概略配置設計として必要な回路レイア ウト設計との協調が可能になっており，図 6 に示すよう な熱設計と回路設計のパレート解の導出も可能になって いる，今後は，手法のポリッシュアップ，適用範囲の拡 大に留まらず，パレート解からの仕様に基づく総合評価 による意思決定支援, 最終の詳細設計手法へのリンク, 各種要素技術の生産コスト等の経済モデルとの連携, 現 存しない要素技術開発のリスク等も含んだ, トータルシ ステムデザインへと発展させていけると考えている.

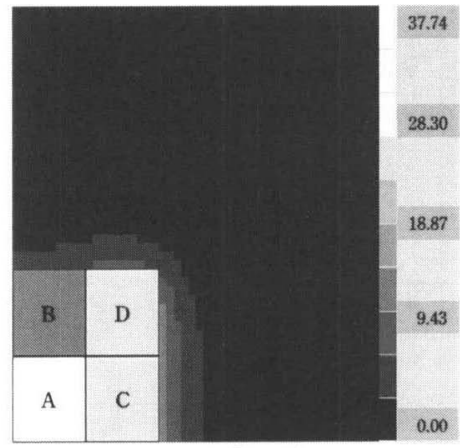

(a) 初期配置

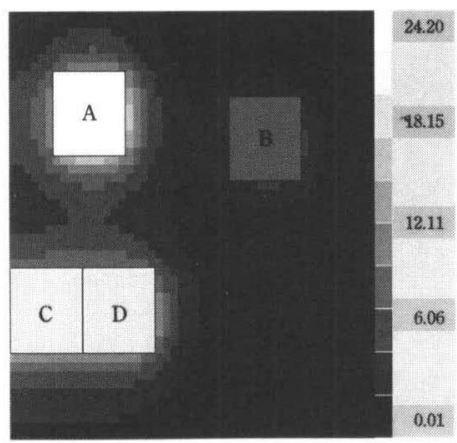

(d) 第6ステップ後の配置

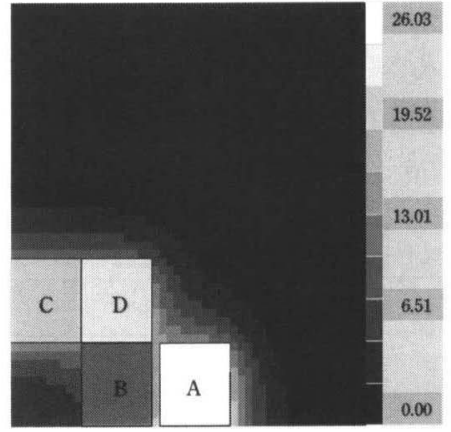

(b) 第1ステップ後の配置

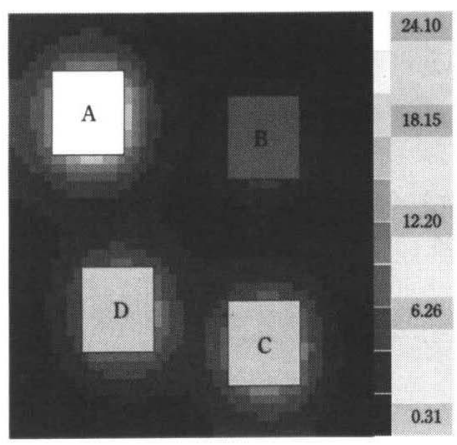

(e) 第7ステップ後の配置

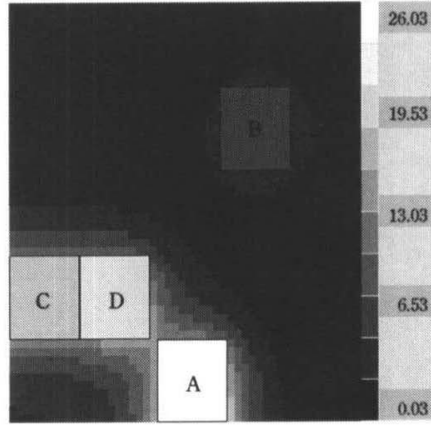

(c) 第 5 ステップ後の配置

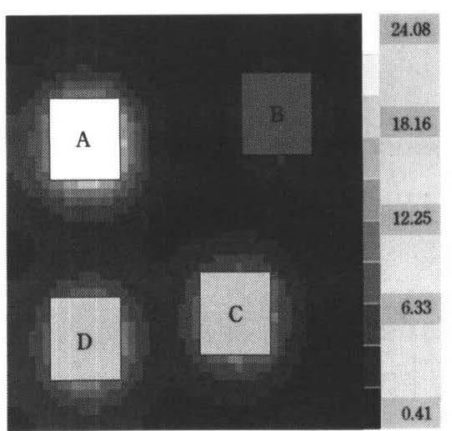

(f) 最終ステップでの配置（設計解）

図 5 階層化設計による設計過程（設計時間約 100 秒） 


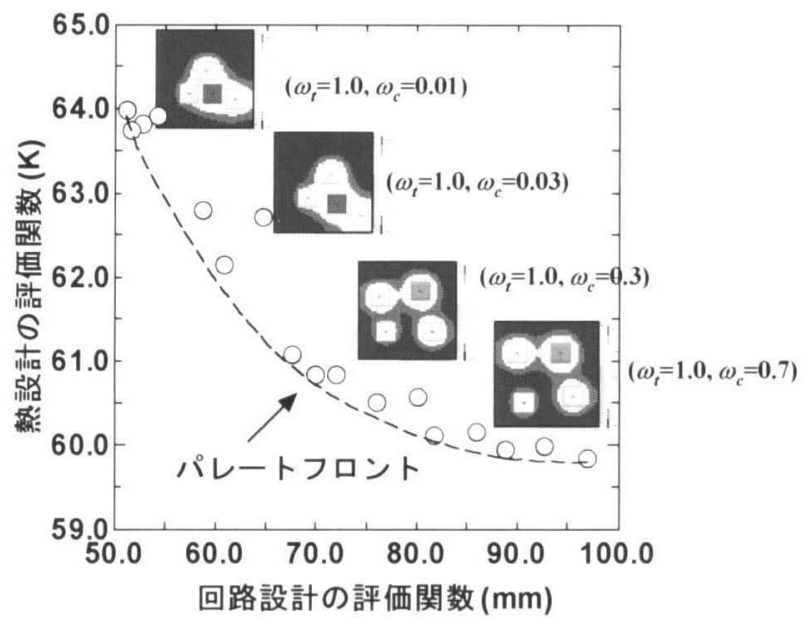

図 6 熱·回路協調パレート設計解

\section{5. 最 後に}

この先致命的に複雑度を増していくシステムのデザイ ンを行っていく上で課題となる複雑系の設計の重要度は, 増大する.

今後はこの手法を基盤として, 複雑系における最適化 手法の一般論の構築と体系化をめざし，ひいてはシステ ムデザイン・インテグレーション手法の構築と体系化に つなげ，これからの日本の物作りに貢献していければと 考えている.

\section{参考文献}

1) Yoshimura, Masataka, Nishiwaki, Shinji, Izui, Kazuhiro, A concurrent design method for multiple cross-sectional automotive body frames involving discrete and continuous design variables, Proceedings of the ASME Design Engineering Technical Conference, Vol. 2 B (2003), pp. 785-793.

2) Takezawa, Akihiro, Nishiwaki, Shinji, Izui, Kazuhiro, Yoshimura, Masataka, Structural Topology Optimization Using Function-oriented Elements Based on the Concept of First Order Analysis, Proceedings of the ASME Design Engineering Technical Conference, Vol. 2 A (2003), pp. 673682.

3) Kojima, Yoshio, Nishigaki, Hidekazu, Sugiura, Hideki, Nishiwaki, Shinji, Kikuchi, Noboru, First Order Analysis for Automotive Designs, ASME, Dynamic Systems and Control Division, Vol. 70 (2002), pp. 179- 187.

4) Cetin, Onur L., Saitou, Kazuhiro, Nishigaki, Hidekazu, Nishiwaki, Shinji, Amago, Tatsuyuki, Kikuchi, Noboru, Modular structural component design using the first order analysis and decomposition-based assembly synthesis,
ASME, Design Engineering Division, Vol. 112 (2001), pp. $131-140$.

5) Yaniv Tal, "An Improved Two-Resistors Compact Thermal Model By Means of Modified Top-Surface-Area”, 18th IEEE SEMI-THERM Symposium, pp. 64-70, 2002.

6) Torsten Hauck and Tina Bohm, Thermal RC-Network Approach To Analyze Multichip Power Packages IEEE SEMI-THERM Symposium, pp. 227-234, 2000.

7) H. I. Rosten, "DELPHI-A status report on european-funded project for the development of libraries physical models for an integrated design environment", 46th ECTC, pp. 172$185,1996$.

8) Xuejun Fan, Development, Validation, and Application of Thermal Modeling for a MCM Power Package 19th IEEE SEMI-THERM Symposium, pp. 144-150, 2003.

9) S. Jain et al, "PCB Layout Design Using a genetic Algorithm”, ASME Design Engineering Technical Conference, DE-Vol. 82, pp. 529-536, 1995.

10) Y. Fukumoto, S. Miura, H. Ikeda, T. Nakayama, S. Tanimoto and H. Uemura, "A Method of Automatic Placement that Reduces Electromagnetic Radiation Noise from Digital Printed Circuit Boards", IEEE Trans, on EMC, pp. 363-368, 2000.

11) Hua Xiang, Xiaoping Tang, Martin D. F. Wong, "Bus-Driven Floorplanning”, Computer Aided Design International Conference on Nov. 2003, pp. 66-73, Nov. 2003.

12) C. -M. Ko, Y. -J. Huang, S. -L. Fu, "Generic Algorithm for MCM Placement", International Conference of Electronics Packages, ICEP, pp. 128-133, 2005.

13) Koichi Ohtomi, "Importance of Upstream Design in Product Development and Its Methodology", 6th Int. Conf. on Thermal, Mechanical and Multiphysics Simulation and Experiments in Micro-Electronics and Micro-Systems, EuroSimE 2005, pp. 17-18, 2005.

14）中岡邦夫, 小林 孝, 堺 宏明, 山中康弘, 堀越美香, 「製品設計の現場で使うフロントローディング設計」, エレ クトロニクス実装学会誌 Vol. 7 No. 7, pp. 564-568, 2004.

15) York C. Gerstenmaier, Gerhard K. M. Wachutka, “Transient Temperature Fields With General Nonlinear Boundary Conditions in Electronics Systems", IEEE CPMT, Vol. 28, No. 1, pp. 23-33.

16) 岩田剛治, 林真太郎, 山本修平, 佐藤了平, 藤本公三, 「モジュール分割における境界条件に着目した初期解析手 法 (FOA) の構築（解析・最適化手法の統合による初期設 計手法の構築 (第 1 報)) 」, 日本機械学会論文集 (C) 編, Vol. 71, No. 707, p. 139-145.

17）林真太郎, 岩田剛治, 藤本公三, 佐藤了平, 「モジュール 分割モデルを用いた高速・概略熱解析一熱・回路協調を考 慮した概略部品配置の自動設計一」, 電子情報通信学会論 文集, Vol. J88-C, No. 11, pp. 964-971.

18）林真太郎, 岩田剛治, 藤本公三, 佐藤了平, 「モジュール 間境界条件に基づく解析・設計による熱・回路協調設計一 熱・回路協調を考虑した概略部品配置の自動設計一」, 電 子情報通信学会論文集, Vol. J88-C, No. 11, pp. 972-980. 